\section{Straight to the heart with Viagra}

Sildenafil, a popular drug used for erectile dysfunction, aids the enlargement of one organ but may inhibit that of another. New research by Eiki Takimoto and colleagues ${ }^{1}$ demonstrates that sildenafil suppresses myocardial hypertrophy in the face of chronic increased cardiac afterload. Their findings also provide clues as to how cardiac myocyte hypertrophy occurs.

Cardiac hypertrophy usually occurs in patients to compensate for increased cardiac afterload resulting from systemic hypertension. Unfortunately, this can be maladaptive, resulting in cardiac ischemia and heart failure. The process is mediated by proteins that signal and respond to these changes in pressure; some of these proteins have been proposed as potential therapeutic targets, ${ }^{2}$ but few have been directly studied with drug inhibition.

One of these is guanosine $3^{\prime}, 5^{\prime}$-cyclic monophosphate (cGMP). Sildenafil is an inhibitor of the phosphodiesterase-5A (PDE5A) enzyme, which metabolizes cGMP inside cells. To investigate the effect of sildenafil on cardiac hypertrophy, the researchers constricted the transverse aorta of mice to expose them to increased cardiac afterload. They found that mice given sildenafil did not develop cardiac hypertrophy. Moreover, in mice that acquired cardiac hypertrophy (mean 63\% increase in heart mass), sildenof afil treatment reduced the hypertrophy to baseline levels.

Takimoto and colleagues went on to show that by inhibiting PDE5A and thereby raising the levels of cGMP inside cells, the activity of intracellular pro- tein cGMP-dependent protein kinase G type-1 (PKG-1) was increased. The role of this protein in regulating cardiac hypertrophy is unclear, but the results suggest that it could be a target for future drug development.

\section{References}

1. Takimoto E, Champion HC, Li M, Belardi D, Ren S, Rodriguez ER, et al. Chronic inhibition of cyclic GMP phosphodiesterase $5 \mathrm{~A}$ prevents and reverses cardiac hypertrophy. Nature Med 2005;11(2):214-22.

2. Frey N, Katus HA, Olson EN, Hill JA. Hypertrophy of the heart: a new therapeutic target? Circulation 2004;109(13):1580-9.

\section{Targeting hard-to- treat cancers}

For most patients with chronic myelogenous leukemia (CML), chemotherapy with imatinib results in a complete hematologic and cytogenetic response. However, patients who acquire drugresistant CML have a poor prognosis. Ellen Weisberg and colleagues recently identified the mechanism for imatinib resistance and have designed a new drug that may overcome the problem.

The Philadelphia chromosome is uniformly present in CML. A hybrid gene on the chromosome, $\mathrm{Bcr}-\mathrm{Abl}$, codes for an abnormal tyrosine kinase protein that triggers the uncontrolled proliferation of CML cells. By inhibiting the tyrosine kinase protein, imatinib suppresses the proliferation and induces apoptosis in $B c r-A b l$ positive cell lines. Resistance to imatinib is associated with mutations in the protein Bcr-Abl that reduce the effectiveness of treatment. ${ }^{2,3}$ After examining the detailed structure of the binding mechanism of imatinib to $\mathrm{Bcr} / \mathrm{Abl}$, the researchers were able to design a drug, AMN107,

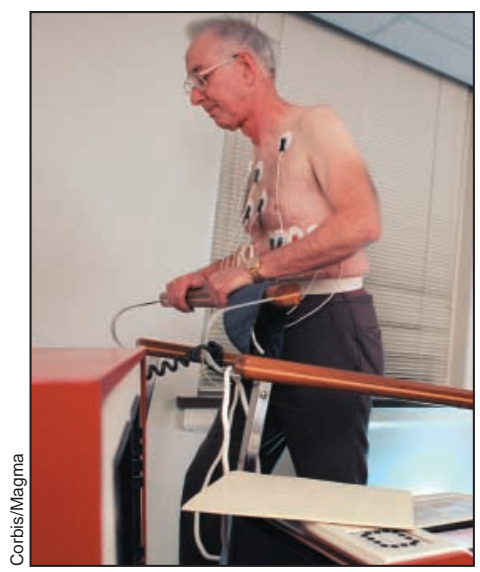

Is sildenafil good for the heart?

that induced a 10 - to 50 -fold greater inhibition of the gene in in-vitro experiments with human CML cell lines. More important, they demonstrated that AMN107 can inhibit mutant Bcr-Abl proteins that are resistant to imatinib both in vitro, in human cells, and in vivo, in experiments using mice. Finally, they found no evidence of drug toxicity.

The authors ${ }^{1}$ state that AMN107 is poised to be studied in phase I clinical trials. It is hoped that this drug will prove useful in overcoming the deadly problem of drug resistance and that the methods used by these authors will prove to be a model for the design of future cancer drugs. David Secko, Vancouver

\section{References}

1. Weisberg E, Manley PW, Breitenstein W, Bruggen J, Cowan-Jacob SW, Ray A, et al. Characterization of AMN107, a selective inhibitor of native and mutant Bcr-Abl. Cancer Cell 2005;7:129-40.

2. O'Dwyer ME, Mauro MJ, Kurilik G, Mori M, Balleisen S, Olson S, et al. The impact of clonal evolution on response to imatinib mesylate (STI571) in accelerated phase CML. Blood 2002;100:1628-33.

3. Hochhaus A, La Rosee P. Imatinib therapy in chronic myelogenous leukemia: strategies to avoid and overcome resistance. Leukemia 2004;18(8):1321-31. 